\title{
Factors causing Mathematics Anxiety of Senior High School Students in Calculus
}

\author{
Aldrin John J. Estonanto ${ }^{1} *$ Dr. Ryan V. Dio ${ }^{2}$ \\ ${ }^{1}$ Technology Department, Sorsogon State College \\ Sorsogon City, Philippines \\ ${ }^{2}$ School of Graduate Studies, Sorsogon State College \\ Sorsogon City, Philippines \\ *Corresponding author's email: aldrinestonanto [AT] gmail.com
}

\begin{abstract}
Mathematics anxiety impacts to the learner tremendously especially his scholastic performance, mastery of learning competencies and skills, and even the career choice. This study investigated the different factors causing mathematics anxiety in Calculus of senior high school students. The research design employed was mixed method. Qualitative techniques were used in determining the factors that caused the anxiety of the participants and descriptive design in determining the anxiety level of the students. The study was conducted in five (5) senior high schools offering Science, Technology, Engineering and Mathematics (STEM) Strand in a province in the Southern Luzon, Philippines. Sixty- nine(69) participants took the Mathematic Anxiety Inventory (MAI) developed by Plake and Parker. The results revealed that almost all of the participants have either high or moderate mathematics anxiety level. The paper concludes that the abstract mathematical concepts of Calculus, the teaching style and attitude of the teacher, and the poor comprehension and analytical skills of the students were the major factors that caused the mathematics anxiety of the participants.
\end{abstract}

Keywords - mathematics anxiety, factors, calculus, senior high school, STEM strand

\section{INTRODUCTION}

It is a common knowledge that mathematics is an unpopular subject among Filipino learners. The usual notion that mathematics is a very difficult subject that must be evaded if possible is also widespread to students. Educators termed this negative attitude of learners towards mathematics subject mathematics anxiety. Mathematics anxiety is defined by Richardson and Suinn (1972) as feelings of tension and anxiety that interfere with the manipulation of numbers and the solving of mathematical problems in a wide variety of ordinary life and academic situations. Tobias(1980), one of the pioneering researchers of this subject, described it as the panic, helplessness, paralysis and mental disorganization that arises among some people when they are required to solve a mathematics problem. Students who manifest this anxiety are usually anxious of doing their mathematics and always afraid of receiving a failing grade in this subject. Physical manifestations such increased heart rate, restlesness, clammy hands, easily fatigued, upset stomach, muscle tension, and light headedness are easily observed. The person who suffers from math anxiety also usually manifests psychological symptoms such as irritability, difficulty in concentrating, and feeling of helplessness, worry and disgrace. The behavioral signs noticeable by classroom teachers include habitual absenteeism and tardiness, avoidance of math classes, lack of interest to participate in classroom discussions, putting off math homeworks, and poor study habit in math subjects (Le Moyne, 2003; Woodard, 2004; Jackson, 2008; Mission College, 2009; Plaisance, 2009).

Since 1970s, there was a growing interest among educational investigators on conducting researches on the subject of math anxiety because its impact on the learning process of numerical skills of students (Richardson \& Suinn, 1972; Tobias \& Weissbrod, 1980; Hembree, 1990; Ma \& Kishor, 1997; Ma, 1999). In an attempt to delineate the nature of mathematics anxiety, some researchers discovered that it begins mostly while pupils are still in elementary years, and the peak of its symptoms manifest in secondary and senior high school level (Ashcraft, 2002; Rameau \& Louime, 2007; Scarpello, 2007; Legg \& Locker, 2009; Sun \& Pyzdrowski, 2009; Geist, 2010). Jain and Dowson(2009) pointed out the learner's lack of ability to handle frustrations, the negative parent and teacher attitudes toward mathematics, and the excessive emphasis of teachers on routines and drills, and the habitual absenteeism among pupils in math classes as primary causes of mathematics anxiety. Turner and colleagues (2002) and Scarpello (2007) stressed that there is a strong link between the educational attainment and attitudes towards mathematics of the parents to the level of mathematics anxiety of their children. Other researchers, on the other hand, reported that the overreliance of mathematics teachers on 
time- pressured tests, graded recitation, rote memorization, drills and chalk- board method are the major factors contributory to the anxiety of children (Thilmany, 2004; Scarpello, 2007; Tsui \&Mazzocco, 2007; Popham, 2008; Finlayson, 2014). The classic model of Cemen(1987) explicated dispositional antecedents (for example: lack of confidence), environmental antecedents (for example: negative experiences in math), and situational antecedents (for example: classroom situations) as reasons for developing anxiety in math. Following other educational investigators, Devine and colleagues(2012) classified the variables that are related to mathematics anxiety development namely environmental variables (e.g. negative experiences in class or family), intellectual variables (e.g. cognitive ability of the learner), and personality variables (e.g. self- concept of the learner). Consequently, it can be said that the causes of mathematics anxiety are most likely multifactorial in origin.

Several studies revealed that mathematics anxiety impacts to the learner tremendously especially his scholastic performance, mastery of learning competencies and skills, and even the career choice (Richardson \& Suinn, 1972; Tobias \& Weissbrod, 1980; Hembree, 1990; Ma \& Kishor, 1997; Fennema \& Sherman, 1977; Wigfield \& Meece, 1988; Miller \& Bichsel, 2004; Estonanto, 2017). Because of this, it is of great significance for educators to investigate this research subject since a lot of literatures suggest that this anxiety impedes the limitless potential of learners to excel in mathematics.

\section{RESEARCH QUESTIONS}

This study investigated the causes of the mathematics anxiety of senior high school students in Calculus. The paper attempts to present the answers to the following research questions:

1. What is the level of mathematics anxiety of the students?

2. What are the factors that caused the mathematics anxiety of the participants?

\section{METHODOLOGY}

This study was part of a series of studies conducted by the researchers about mathematics anxiety of students in senior high school. The study was conducted in five (5) senior high schools offering Science, Technology, Engineering and Mathematics (STEM) Strand in a province in the Southern Luzon, Philippines. This study made use of mixed method research design. Qualitative techniques such as small group discussion, unstructured interview and open- ended questionnaires were used in identifying the factors that caused the mathematics anxiety of the participants. Descriptive design was utilized in determining the level of anxiety of the participants.

The Mathematics Anxiety Inventory (MAI) developed and validated by Plake and Parker (1982) was administered to sixty- nine (69) senior high school students purposively selected with the help of their respective classroom Calculus teachers and guidance counselors. Only those students who manifested at least three behavioral symptoms of mathematics anxiety for the time lag of six months (June 2017- January 2018) were identified as subjects of this study (Le Moyne 2003). A waiver signed both by the students and parents giving consent and permission to participate in the study were secured by the researcher, and students who did not give their consent were not involved in the sample. Utmost anonymity and confidentiality of the results were applied in the treatment and analysis of the data to uphold ethics in research and protect the rights of the participants.

To interpret the weighted average MAI scores of the participants, the following scale was used:

$\begin{array}{cc}\text { Anxiety Score } & \text { Interpretation } \\ 1.00-1.80 & \text { Very Low Anxiety } \\ 1.81-2.60 & \text { Low Anxiety } \\ 2.61-3.40 & \text { Moderate Anxiety } \\ 3.41-4.20 & \text { High Anxiety } \\ 4.21-5.00 & \text { Very High Anxiety }\end{array}$

\section{RESULTS AND DISCUSSIONS}

This section presents the discussion of the results in this study. The analysis of the results is divided into two parts: level of anxiety of the participants, and factors that caused mathematics anxiety.

\subsection{Level of Mathematics Anxiety of Participants}

The anxiety level of an individual in mathematics varies depending on the extent of avoidance and negative attitudes the student exhibits towards the subject. Table 2 presents the mathematics anxiety level of the participants based on the computed results of the MAI. 
As shown in table 2, among the students observed by their mathematics teachers who manifested symptoms for mathematics anxiety, $49.28 \%$ have high anxiety, $34.78 \%$ have moderate anxiety, $10.14 \%$ have very high, and both $2.90 \%$ have low and very low anxiety.

Table 2. Level of Mathematics Anxiety of Students

\begin{tabular}{cccc}
\hline Level & f & $\%$ & Rank \\
\hline Very High & 7 & 10.14 & 3 \\
High & 34 & 49.28 & 1 \\
Moderate & 24 & 34.78 & 2 \\
Low & 2 & 2.90 & 4.5 \\
Very Low & 2 & 2.90 & 4.5 \\
Overall & 69 & $100 \%$ & \\
\hline
\end{tabular}

MAI results revealed that the majority of the participants have moderate to very high anxiety in mathematics which is consistent with the observations of their respective Calculus teachers (see table 2). The observed behavioral symptoms like restlessness, easily fatigued, difficulty in concentrating, irritability, and muscle tension identified by the teachers were reinforced by this result which supports that these students have mathematics anxiety (Le Moyne 2003).

Table 3. MAI Results of Participants

\begin{tabular}{|c|c|c|}
\hline Situation & $\begin{array}{c}\text { Anxiety } \\
\text { Weighted } \\
\text { Score }\end{array}$ & Description \\
\hline 1 Watching a teacher working an equation on the board & 2.96 & Moderate \\
\hline 2 Buying a mathematics book & 2.08 & Low \\
\hline 3 Reading and interpreting graphs and charts & 3.21 & Moderate \\
\hline 4 Enrolling a course in mathematics & 3.37 & Moderate \\
\hline 5 Listening to a student explain a mathematics formula & 2.88 & Moderate \\
\hline 6 Entering a mathematics classroom & 3.38 & Moderate \\
\hline 7 Looking through pages in mathematics textbook & 3.04 & Moderate \\
\hline 8 Starting a new chapter in mathematics book & 3.17 & Moderate \\
\hline 9 Walking around campus and thinking about a mathematics class & 2.94 & Moderate \\
\hline 10 Picking up a mathematics textbook to begin working a homework & 3.08 & Moderate \\
\hline 11 Reading the word "mathematics" & 2.53 & Low \\
\hline 12 Working on mathematicsematical problem & 3.57 & High \\
\hline 13 Reading a formula in mathematics & 3.29 & Moderate \\
\hline 14 Listening to lecture in a mathematics class & 3.43 & High \\
\hline 15 Having to use the table at the back of a mathematics book & 3.40 & Moderate \\
\hline 16 Being told to work a problem in quadratic equation & 3.25 & Moderate \\
\hline 17 Being given homework of many difficult problems & 4.06 & High \\
\hline 18 Thinking about an upcoming mathematics test one day before & 4.34 & Very High \\
\hline 19 Solving square root problems & 3.18 & Moderate \\
\hline 20 Taking a major exam in mathematics & 4.53 & Very High \\
\hline 21 Getting ready to study for a mathematics test & 3.74 & High \\
\hline 22 Being given a surprise quiz in mathematics & 4.47 & Very High \\
\hline $\begin{array}{l}23 \text { Waiting for the result of a mathematics test returned in which you are expected to } \\
\text { do well }\end{array}$ & 4.07 & High \\
\hline 24 Taking a final exam in mathematics & 4.08 & High \\
\hline Overall & 3.43 & High \\
\hline
\end{tabular}


Furthermore, as reflected in table 3, which displays the itemized MAI results, only two from the 24- item anxiety test the participants registered low anxiety level while on the remaining 22 items the participants were overwhelmingly found to have moderate to very high anxiety level.

The only MAI items (see table 3) in which the participants scored very high anxiety level were items \#18(Thinking about their upcoming mathematics test one day before the exam), \#20(Taking a major exam in mathematics), and \#22(Being given surprised quizzes).

The results revealed are consistent with the findings on factors that caused the mathematics anxiety of the students discussed earlier (see figure 1). In the previous discussions about factors of mathematics anxiety, being given with very difficult surprised quizzes and time-pressured tests contributed to the fear of the students in the subject Calculus. Some students even mentioned that obtaining very low test results in Calculus is traumatic to them.

Additionally, on items \#12(Working on mathematical problem), \#14(Listening in a lecture in mathematics class), \#17(Being given homeworks of many difficult problems), \#21(Getting ready for a mathematics test), \#23(Waiting for the result of mathematics test in which the student is expected to do well), and \#24(Taking a mathematics test) the students registered with high level of mathematics anxiety. These results are again consistent with the findings revealed in figure 3 earlier. The students experience high anxiety when they are working on mathematical problems and about to take tests because they understand their poor skills in comprehension and analysis would lead them to failure. Moreover, the too much emphasis of teachers on many paperworks such as lengthy homeworks is also a factor that contributes to mathematics anxiety.

These results support the findings showed on figure 1 that too much dependence on difficult time- pressured tests and frequent lengthy surprised quizzes causes mathematics anxiety. Similarly, together with item \#12(Working on mathematical problem), they also back up the result that poor comprehension and analysis of students result to anxiety as well. Because students with mathematics anxiety perceive that Calculus contain concepts that are very abstract for them to understand, this negative perception along with fear of failure worsen by their poor analytical skills would normally affect their self- confidence, which later develops into fear of mathematics tests.

Likewise, MAI results on items \#14(Listening in a lecture in mathematics class) and \#23(Waiting for the result of mathematics test in which the student is expected to do well) also reinforce the idea that teaching strategies and pressure from other people are contributory to mathematics anxiety.

These results are similar to the findings of Sutter (2006) and Tobias (1988) which revealed that mathematics anxiety is common among elementary and high school learners. The former found out that students with medium anxiety and above have used strategies most which result from their high need, whereas the latter revealed that cultural and environmental factors such as gender stereotyping could have caused mathematics anxiety of female learners who have higher anxiety level than males.

\subsection{Factors that Caused Mathematics Anxiety of Participants}

There are several reasons why mathematics anxiety develops to students of Calculus. Figure 1 demonstrates the factors that caused mathematics anxiety as identified by the respondents. The answers of the participants gathered through focused group discussion, guided interview, and written responses were analyzed through thematic approach model. The researcher was able to identify eight (8) thematic areas which were labeled in this paper as emerging themes based on the responses of the students.

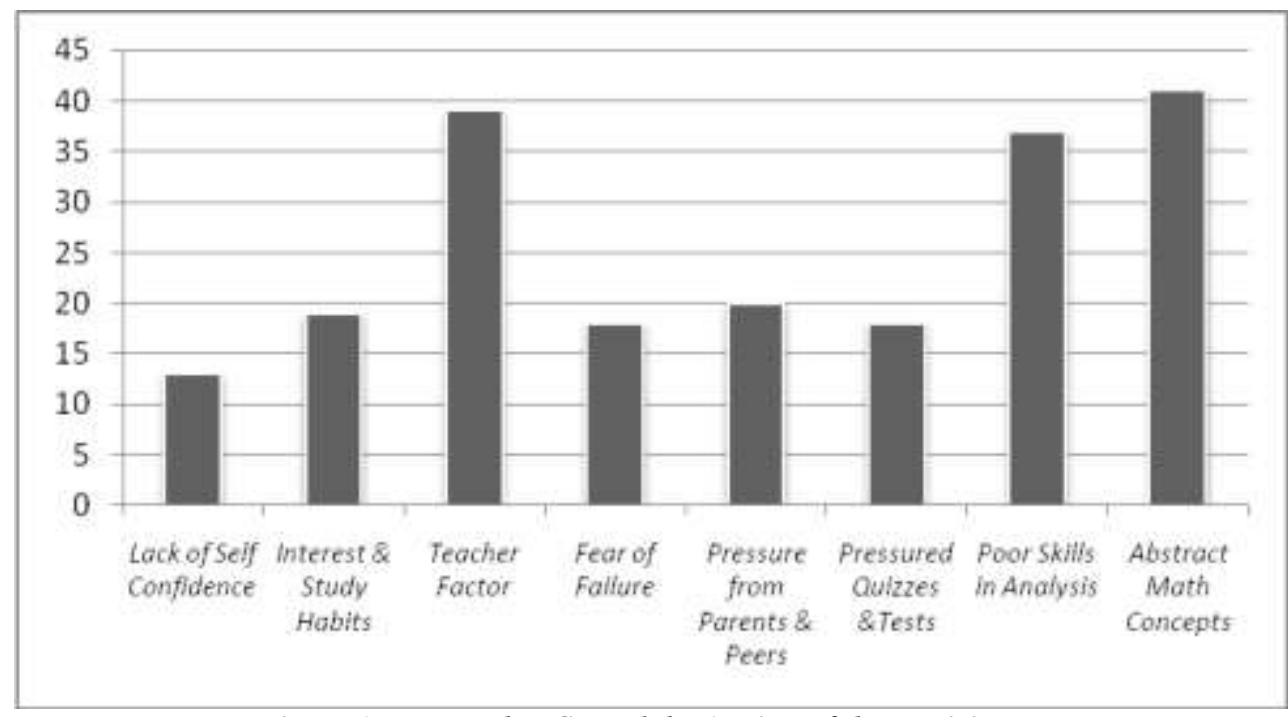

Figure 1. Factors that Caused the Anxiety of the Participants 
For the 69 participants of this study, mathematics anxiety developed due to varied situations with mostly connected to factors related to psycho- socio learning environment (see figure 1). Forty-one responses linked to the Abstract Mathematical Concepts of Calculus the cause of their anxiety, 39 responses associated their fear of calculus to the negative experiences they had with their teacher (Teacher Factor), 37 responses connected mathematics anxiety to their Poor Skills in Comprehension and Analysis of word problems, 20 responses to High Expectations of Parents and Peers, 19 responses to problem on Personal Interest, Motivation and Study Habits, both 18 responses to Fear of Failure, and to Fear of Difficult and Time- pressured Tests, and lastly, 13 to Lack of Self- confidence.

\subsubsection{Abstract Mathematical Concepts}

Calculus has many abstract mathematical concepts which most students find difficult to comprehend. As reflected in Figure 3, the fear for these Abstract Mathematical Concepts is the top factor (rank 1) identified by the respondents as the cause of their anxiety. Newstead(1995) referred to this factor as the "innate characteristics of mathematics" which encompass the general nature of mathematics as a subject that requires critical thinking, logic, problem solving, and analysis of abstract concepts.

The dominant remarks of the participants is that Calculus becomes very difficult to them because of several notations, symbols, variables, expressions, equations, laws, theorems, and unfamiliar mathematical languages involved in understanding Calculus lessons.

"Pag dating kasi ng highschool, iba na ang mukha ng mathematics (Because starting in highschool, mathematics became different). It started when algebra and trigo were introduced." (Student from Cohort A)

"May mga letters na $x, y, z$ na ina- add maliban pa sa numbers... (Because of letters in math that are being added in addition to mere numbers)" (Student from Cohort $B$ )

"...Because the lesson suddenly shifted from $1+15$ to $x^{2}+2 x^{2}+2$, and I get easily weak hearted!"

(Student from Cohort D)

Based on the responses, it could be deduced that the participants were anxious of the subject because they lack conceptual understanding of the mathematical principles particularly the foundational language of algebra and its basics. Most of the students, from the moment they encounter equations and variables, they start "swallowing their saliva", as how they describe it, which clearly manifests anxiety. There are also participants who admitted during the focused group discussion that whenever they hear "differentiation" and "integrals", they start feeling nervous, restless, worried and anxious. Some also added they oftentimes found it hard to concentrate during board works and graded recitations, and they felt tensed and their mind went blank once tasked by the teacher to solve equations in front of the class. These students must had learned the computational skills such as memorization of formulae and manipulation of symbols, but had not fully understood the concepts themselves and their practical applications (Das \& Das, 2013; Skemp, 1986 ). It could also be that the participants did not understand and master at all both the conceptual skills, and computational and manipulative skills of equations in mathematics as evident by their responses:

\section{“Lessons are so hard, I can't understand them!” (Student from Cohort C) \\ "After discussion, I always start thinking how did it happen! The subject itself is so hard and the equations." (Student from Cohort E) \\ "Ang hirap hirap intindihin ang math (It's so hard to understand math)... it started when letters were incorporated in formulas and equations." $\quad$ (Student from Cohort B)}

It is implied in the responses of the participants that they are afraid of the subject because they do not have the mastery of fundamentals of manipulating equations. This would mean as well that these students must not have attained the proficiency level in applying the foundational laws, theorems and properties of algebra as they find understanding equations difficult. The basic concepts on laws of exponents, polynomials, integers, rational expressions, radicals, properties of numbers and equality, and translating words into algebraic notations had not been fully grasped resulting to deliberate avoidance of equations and mathematical symbols.

The difficult, lengthy, multiple- steps, irrelevant, unrealistic, complex, sophisticated and time- pressured word problems that usually require sharp comprehension, logical reasoning, and critical analysis was also identified by the participants as being another source of their anxiety. For the respondents, a worded problem that would take them three whole hours just in solving makes them felt irritable, impatient, confused, and easily annoyed. On the other hand, allocating too short period of time for problems that must require longer time duration have the same impact to them. The common practice in mathematics classrooms of giving "Americanized word problems" and covering textbook problem by problem, intensify the anxiety of the students(Oberlin, 1982). "Americanized problems" are word problems that are contextualized in American setting. Most word problems in Filipino mathematics textbooks contain vocabulary words and examples which are irrelevant to the context and personal experiences of Filipino learners. The use of unfamiliar words such as "dime" and other foreign currency and units without any hint or clue as well as places, buildings, and people not known to Filipino learners were indicated by the participants as factors that add to the vagueness, ambiguity 
and difficulty of problem solving in mathematics. Furthermore, mathematics is least popular to students due to its emphasis on sole correct answer which is in contrast to other subjects that oftentimes tolerate respect for opinions and appreciative for other ideas(Stuart, 2000).

“...step by step please...don't just give a brief explanation, the world of mathematics is much complicated so it requires a teacher with elaborative skills that will help the students to learn well which will lead them to become confident and avoid anxiety." (Student from Cohort B)

Patient slow- paced step- by- step discussion of the solution to word problems, however, and an approach that is sensitive to the needs of the slow learners was well appreciated by the participants.

\subsubsection{Teacher Factor}

The participants of this study also named Teacher Factor (rank 2) as major cause of their anxiety. This factor covers both the teaching strategies and pedagogical practices, and the personality and attitude of the teacher inside the classroom environment.

For the participants, mathematics anxiety developed because of unconstructive teacher practices in traditional mathematics classrooms (Finlayson, 2014). The usual directive- authoritarian approach used by most teachers was also contributory. The learning process becomes a one- way process where the teacher delivers the lesson through chalkboard lectures and the students will receive the information. According to participants, most of their mathematics teachers seldom used colorful instructional materials, information communication technology and other engaging learning activities, but instead had always resorted to discussions, giving boardworks, drills, assignments, projects, worksheets, graded recitations and time- pressured surprised quizzes.

Other classroom practices the participants associated to their mathematics avoidance were the common teachers' routines of get- your- book- copy- this approach, bombarding students with quizzes and seatworks everyday, insisting that the textbook is always right or bookishness, prohibiting students from using softwares and calculators, and giving more tasks as punishment for misbehaviors of students which is similar to the conclusions of Oberlin (1982).

Another common practice indicated by the students was the "cover- to- cover approach" of teachers. As revealed by the students, in mathematics class, they were oftentimes forced to study all topics in the coverage for the whole grading period regardless of whether the target competencies have been mastered or not. Bound to finish topics set in their periodic learning plans, most teachers usually procrastinate to discuss the remaining topics yet to be discussed in order to catch the coverage.

As stressed by Finlayson (2014), the teaching style of mathematics educators in traditional classrooms is a major cause of the anxiety of the students. When the main focus of the teacher is to complete all the required topics set by the curriculum rather than complete the learning of the students, then the mathematical skills acquired by the students become half- baked. These daily routines and common practices of traditional mathematics teachers made students more prejudice of mathematics.

\section{"May bagong topic na kahit di pa nga nage-gets ang nauna. (There's already a new topic even we haven't yet mastered the previous)" (Participant from Cohort A) \\ "...the teacher moves on to the next lesson even not everyone has mastered the lesson! She explain very very fast because she want to cover the whole chapter." (Participant from Cohort D) \\ “...ayoko pag ang teacher ay naghahabol ng lesson. (I don't like teachers who fasttracks the lesson to finish the coverage)... because of teacher who doesn't care whether his students can follow/ cope up."}

(Participant from Cohort E)

Additionally, teachers with minimal abilities in delivering lessons effectively as well as poor pedagogical skills were also noted in the interviews that which instigates anxiety. Students claimed that they sometimes noticed their teachers either unprepared to discuss the topics in Calculus, have no mastery of the subject matter, or with insufficient knowledge of the subject being taught. The observation of the participants was that, teachers who have no holistic expertise of the subject matter usually resorted to fast- paced discussion, fond of using "from the book- by the book approach", irritable and not willing to entertain questions and clarifications from the students, and insensitive to the needs of the learners.

"Masyadong mabilis ang teacher magsalita kaya di maintindihan...di pa magaling mag-explain! (The teacher speaks very fast that's why it's hard to understand. She also lacks skill in explaining the lesson clearly)"

(Student from Cohort E)

“...boring magturo, nakakatamad pumasok... Di niya alam ang tinuturo niya nagagalit pa po kung tinatanong namin.(She has boring teaching style, it makes me lazy to attend her class... she lacks mastery of the subject matter and becomes angry when asked about the lesson.) Many of us skip her class!"

(Student from Cohort A) 
Implicit to observations of the participants on low mastery of doing mathematics by their teachers is the assumption that these teachers themselves are not confident of their own mathematical abilities (Finlayson, 2014). It can be said that these teachers had produced mathematics anxiety among their students because they are anxious of their own mathematics themselves, or it could be that they are not good in mathematics themselves (Burns, 1998; Stuart, 2000, Lee-Chua, 2005).

Likewise, the autocratic- disciplinarian role of the teacher in the classroom was also highly connected by the respondents to anxiety. They complained they had traumatic experiences with their previous mathematics teachers whom they described as either very strict, "terror", "iron- ruler", unfair, insensitive, rude, unaccommodating and uncompromising. Some respondents declared their anxiety started when once their teacher embarrassed them in front of their classmates due to inability to render correct solutions to mathematics problems.

Other teacher- related incidences noted were mathematics teachers shouting at misbehaving students, ridiculing and scolding students before the class, punishing the whole class for one's misconduct, threatening students with failing grade, humiliating inattentive learners during lectures, and other unpsychological approaches that degrade and exploit the rights and emotional condition of the learners. Notice in the comments of the respondents that the cause of their anxiety was the undesirable attitude and personality of their teachers themselves:

$$
\begin{gathered}
\text { “...when I was in grade } 6 \text { my teacher scolded me and shouted at me and I got scared and } \\
\text { (Participant from Cohort B) } \\
\text { "Teachers in mathematics are very scary! Pinapahiya ka ng teacher (there are teachers who } \\
\text { embarrass students)." (Participant from Cohort C) } \\
\text { "(What causes my anxiety is) my ability to cope with the attitude of the teacher. She has very } \\
\text { high standards, perfectionist and very strict!" } \\
\text { (Participant from Cohort E) }
\end{gathered}
$$

In contrast, teachers whom the respondents depicted as creative, innovative, good speaker with loud voice, dynamic, "not boring", with sense of humor, patient, accommodating, friendly, encouraging, inspiring, kind- hearted, appreciative, loving, considerate, respectful to other opinions and ideas, and sensitive to feelings of others were marked as ideal.
"Refrain from unconsciously embarrassing students when they do not know the answer."
(Student from Cohort A)
“...become more understanding, considerate and patient to students who are unable to answer mathematics problems easily." (Student from Cohort C)
"Study the topic that you'l discuss to your students very well and give some games or activities that make the students understand the topic more faster and the student will enjoy as well as learning."
(Student from Cohort D)

The participants further suggested teachers should also employ collaborative learning, differentiated instruction for various learning styles and individual differences, give group activities, arouse student interests through games, audio- visual materials, manipulatives, give sufficient realistic examples, encourage peer- tutoring, utilization of ICT multimedia in instruction, and use of positive approach in dealing with students. These are also backed by several studies which highlighted innovative teaching strategies utilizing collaborative learning, and humanistic and constructivist approach as opposed to traditional pedagogies (Dewey, 1938; Hackworth, 1992; NCTM, 1995; Hiebert etal., 1997; Zemelman, 1998; Constructivist, 2013).

\section{“...try to cater to learning styles of students, not all of us learn at the same pace." (Student from Cohort E) \\ "Lesson first and then boardwork for each student and the teacher should assist if a student don't know what the next step." (Student from Cohort C)}

The utilization of diverse teaching strategies, varied assessment methods that cater learning styles and multiple intelligences are also considered as best practices in mathematics education; they help mitigate anxiety of learners (Piaget \& Inhelder, 1969; Chapin etal., 2003; Thirteen Ed Online, 2004; Van de Walle etal., 2014).

\subsubsection{Poor Skills in Comprehension and Analysis}

Thirty- seven responses also linked their anxiety to their underdeveloped comprehension and analysis skills. They acknowledged that to perform good in mathematics requires in depth comprehension and analytical understanding of different word problems. The student should be able to analyze the situation and apply correct mathematical principles and formulas that govern it. One student mentioned she has difficulty in connecting the new topic with the previous lessons as well as it's so hard for her to identify which topic must be used to solve the problem. Finding the correct solution is also very hard, another participant added. 


\title{
"I cannot understand the problem neither the solution." $\quad$ (Participant from Cohort B)
}

\author{
“I can't get the correct formula that I must use!" (Participant from Cohort D)
}

\section{"I always become mentally- blocked resulting to slow analysis of mathematics problems and equations (to apply)." (Participant from Cohort D)}

It can be observed in the responses of the participants that majority of them manifested difficulties in demonstrating skills in effectively reflecting on the situation given and critically devising a plan to work out a solution to the problem. Consequently, problem- solving skills would be a factor as well. Implicit to these difficulties is the inability of the students to make a clear mental illustration of the problem they encounter. These students fear problem- solving because they feel their skills in reflective thinking are not that good.

\subsubsection{Other Factors}

The other factors identified by the respondents as reasons for their anxiety are pressure from parents and peers, personal interest and study habits, pressured quizzes and tests, fear of failure, and lack of self- confidence.

Twenty responses connected mathematics anxiety to too much pressure the students receive from their family, peers, and even from the school community itself. There were participants who honestly confessed that their parents would habitually reprimand, punish, nag and shout at them every time they get failing grades in mathematics. Pursuing engineering and accounting courses were also noticed as popular courses for the parents, and another identified reason for their insistence to their children to become achievers in mathematics. Moreover, consistent honor students and MTAP contestants in elementary who experienced lower grades in their secondary algebra classes also cited the unfair high expectations to them as cause of their anxiety.

Another cause for the anxiety of the students is the poor study habits and lack of personal interest in studying mathematics. Majority of the participants who admitted they have anxiety in mathematics were also the same students who demonstrated little or no interest at all in learning mathematics. Some even stated mathematics is their least favorite subject. Unsurprisingly, these participants disclosed their failures on prioritizing their mathematics homeworks, reviewing lessons, studying for exams, making projects and reading mathematics books.

In addition to teacher- related factors discussed above, are the difficult time- pressured quizzes and tests blamed as another reason for the anxiety of the participants. The researcher intentionally separated this theme from teacherrelated factor because there was an observed manifestation from the remarks of the participants that they are extremely opposed to this common practice in traditional mathematics classrooms.

Eighteen identified responses questioned the unjust and excessive emphasis of their mathematics teachers on speed, strictness, repetition, rigidity, and extreme use of paper and pencil tests. One respondent mentioned giving daily quizzes and lengthy written chapter exams as punishment for their misconducts was one contributor to his anxiety. He even escaped mathematics classes because of too much paper works. These findings are similar to study of Curtain (1999) which generalized the pressure of timed examinations and risk of public embarrassment as sources of unproductive tensions among many students.

Furthermore, the fear of failure and lack of self- confidence of students which both have been noted by several researchers (Randhawa etal, 1993; Pajares etal, 1994; Kabiri etal, 2004; Filayson, 2014) were both confirmed in this study. The respondents showed manifestations in their answers that they are anxious of mathematics because they are not confident of their mathematics ability and they are afraid to fail.

Considering the result discussed earlier, mathematics educators may consider these findings that instead of making use of traditional approaches in teaching Calculus, positive approaches and innovative teaching strategies that do away from rigid rote memorization and boring chalk-and-board method may be used. Ausubel's Meaningful Learning Theory(1977) supports the use of games, group activities, ICT and manipulatives in teaching Calculus which would create the learning experiences of students enjoyable and meaningful to them.

Furthermore, the Department of Education may also reconsider the too much emphasis on routines, drills and lengthy paper-and-pen activities on its Calculus modules and textbooks. The study may be used as well as basis in creating policies that ban practices that contribute to mathematics anxiety of the students such as embarrassing students in the class, etc.

\section{CONCLUSION}

The study concludes that almost all of the participants have either high or moderate level of mathematics anxiety. This study established further that the major factors that caused the mathematics anxiety of the students were the difficulty of abstract mathematical concepts of Calculus itself, teacher factor, and poor comprehension and analytical skills of students. 


\section{ACKNOWLEDGEMENT}

The researchers express their profound gratitude to Dr. Helen R. Lara, Dr. Ritzelda A. Deri and Prof. Geraldine F. De Jesus, respective president, vice- president for academic affairs, and campus administrator of Sorsogon State College for their support and encouragement which enabled the authors to finish this humble work.

\section{REFERENCES}

- Ashcraft, M. H. (2002). Math anxiety: Personal, educational, and cognitive consequences. Current Directions in Psychological Science, 11 (5), 181-185.

- Ashcraft, M. H., \& Kirk, E. P. (2001). The relationships among working memory, math anxiety, and performance. Journal of Experimental Psychology, 130 (2), 224-237.

- Ashcraft, MH. \& Krause, J.A. (2007). Working Memory, Math performance, and Math Anxiety, Psychonomic Bulletin \& and Review, 14(2), 243-248

- Ausubel, D.P. (1977).The Facilitation of meaningful verbal learning in the classroom. Educational Psychologist. 12 (2), 162- 178. Retrieved from https://doi.org/10.1080/00461527709529171

- Burns, M. (1998). Math facing an American phobia. Sausalito, CA: Math Solutions Publications.

- Cemen, P.B. (1987). The nature of mathematics anxiety. (Report No. SE 048 689). Stillwater, OK: Oklahoma State University. (ERIC Document Reproduction Service No. ED 287 729).

- Chapin, S. H., O'Connor, C., \& Anderson, N. C. (2003). Classroom discussions: Using math talk to help students learn. Sausalito, CA: Math Solutions Publications.

- Constructivist. (2013). Constructivist Teaching Methods. Retrieved from: http://en.wikipedia.org/wiki/Constructivist_teaching_methods

- Curtain, M. (1999).How to Reduce Math Anxiety in the Classroom at Work and in Everyday Personal Use. New York: Paperback.

- Das, Ranjan \& Das Gunendra C. (2013). Math Anxiety: The Poor Problem Solving Factor in School Mathematics. International Journal of Scientific and Research Publications, Vol. 3, Issue 4, April 2013. ISSN $2250-3153$.

- Devine, A., Fawcett, K., Szücs, D., \& Dowker, A. (2012). Gender differences in mathematics anxiety and the relation to mathematics performance while controlling for test anxiety. Behavioral and Brain Functions, 8, 1-9. doi:10.1186/1744-9081-8-33

- Dewey, J. (1938). Experience and education. New York: Simon \& Schuster.

- Estonanto, A. J. (2017). Impact of Math Anxiety on Academic Performance in Pre-Calculus of Senior High School. Liceo Journal of Higher Education. Liceo de Cagayan University. 13(2), 102-119.

- Fennema, E., \& Sherman, J. (1977). Sex-related differences in mathematicsachievement, spatial visualization, and affective factors. American Educational Research Journal, 14, 51 -7.

- Finlayson, Maureen. (2014). Addressing Math Anxiety in the Classroom. Improving Schools, Vol. 17 (1) 99115. Cape Breton University, Canada.

- Geist, E. (2010). The Anti-Anxiety Curriculum: Combating Math Anxiety in the Classroom. Journalof Instructional Psychology, 37(1). Retrieved from http://www.faqs.org/periodicals/201003/2011820081.html.

- Hackworth, R. D. (1992): Math anxiety reduction. Clearwater, FL: H\&H Publishing. 
- Hembree, R. (1990). The nature, effects, and relief of mathematics anxiety. Journal for Research in Mathematics Education, 21, 33-46.

- $\quad$ Hiebert, J., Carpenter, T. P., Fennema, E., Fuson, K., Wearne, D., Murray, H., Olivier, A., \& Human, P. (1997). Making sense: Teaching and learning mathematics with understanding. Portsmouth, NH: Heinemann.

- Jackson, E. (2008). Mathematics Anxiety in Student Teachers. Practitioner Research in Higher Education, 2(1), 36-42.

- Jain, S. \& Dowson, M. (2009).Mathematics anxiety as a function of multidimensional self-regulation and selfefficacy. Contemporary Educational Psychology, 34(3), 240- 249.

- Kabiri, M. , et.al. (2004). The Role of Self- efficacy, Anxiety,Attitudes and Previous math Achievement in Students' Math Performance. Proceedings of the $3^{\text {rd }}$ International SELF Research Conference, Selfconcept,Motivation and Identity: Where to fromhere? Berlin,4-7.July 2004.

- Lee- Chua, Queena N. (2005). Developing a Problem- Solving Culture in the Philippines. Ateneo de Manila University.

- Legg, A.M., \& Locker, L. (2009). Math Performance and its Relationship to Math Anxiety and Metacognition. North American Journal of Psychology, 11(3).

- Le Moyne College. 2003. Academic Support Center, Retrieved from http://www.lemoyne.edu/academicadvisement/a cademicsupportcenter/mathanx.htm

- Ma, X. (1999). A meta-analysis of the relationship between anxiety toward mathematics and achievement in mathematics. Journal for Research in Mathematics Education, 30, 520-540.

- Ma, X., \& Kishor, N. (1997). Assessing the relationship between attitude toward mathematics and achievement in mathematics: A meta-analysis. Journal for Research in Mathematics Education, 28, 26-47.

- Ma, X., \& Xu, J. (2004). The causal ordering of mathematics anxiety and mathematics achievement: A longitudinal panel analysis. Journal of Adolescence, 27 (2), 165-180.

- $\quad$ Miller, H., \& Bichsel, J. (2004). Anxiety, working memory, gender, and math performance. Personality and Individual Differences, 37, 591-606.

- $\quad$ Mission College. (2009). Overcoming Math Anxiety. Santa Clara, CA. Retrieved from http://salsa.missioncollege. org/mss/stories/storyReader\$9.

- National Council of Teachers for Mathematics (1995). Assessment standards for school mathematics. Reston, Va.

- $\quad$ Newstead, K. (1995). Comparison of young children's mathematics anxiety across different teaching approaches. Unpublished Doctoral dissertation, Cambridge University.

- $\quad$ Pajares, F., \& Graham, L. (1999). Self-efficacy, motivation constructs, and mathematics performance of entering middle school students. Contemporary Educational Psychology, 24, 124-139.

- $\quad$ Piaget, J., \& Inhelder, B. (1969). The psychology of the child. New York: Basic Books, Inc.

- Plaisance, D.V. (2009). A Teacher's Quick Guide to Understanding Mathematics Anxiety. Louisiana Association of Teachers of Mathematics Journal, 6(1). Retrieved from http://www.lamath.org/journal/vol6no1/ anxiety_guide.pdf.

- Plake, B.S., Parker, C.S. (1982 ). The development and validation of a revised version of the Mathematics Anxiety Rating Scale. Educational and Psychological Measurement, 42:551-557.

- $\quad$ Popham, W. J. (2008). Timed tests for tykes? Educational Leadership, 65(8), 86-87. 
- $\quad$ Rameau, P., \& Louime, C. (2007). Mathematics Phobia: Are the mathematical sciences a Pothole in the road of life? Indian Academy of Sciences.

- $\quad$ Randhawa, B.S., et.al. (1993). Role of Mathematics Self- efficacy in the Structural Model of Mathematics Achievement. Journal of Educational Psychology, 85, 41- 48.

- $\quad$ Richardson, F. C., Suinn, R. M. (1972). The mathematics anxiety rating scale: Psychometric data. Journal of Counseling Psychology, 19 (6), 551-554.

- Scarpello, G. (2007). Helping Students Get Past Math Anxiety. Connecting Education and Careers, 82(6), 3435.

- $\quad$ Skemp, R.R. (1986). The psychology of learning mathematics Penguin, Harmondsworth.

- $\quad$ Stuart, V. B. (2000). Math curse or math anxiety? Teaching Children Mathematics, 6(5), 330.

- Suinn, R.M. \& Richardson, F.C. (1972). The Mathematics Anxiety Rating Scale: Psychometric Data. Journal of Counseling Psychology. 19, 39-47.

- Sun, Y., \& Pyzdrowski, L. (2009). Using Technology as a Tool to Reduce Mathematics Anxiety. The Journal of Human Resource and Adult Learning, 5(2), 38-44.

- Sutter, C.M. (2006). The Anxiety Levels and Perceptions of Mathematics Learners from a Midwestern Technical College on Selected Classroom Climate Factors in Mitigating the Effects of Math Anxiety. University of Wisconsin Stout. Retrieved from http://www. uwstout. edu/lib/thesis/2006.

- $\quad$ Thilmany, J. (2004). Beating math anxiety. Mechanical Engineering, 126(12), 18-18.

- Thirteen Ed Online (2004). Constructivism as a paradigm for teaching and learning. Retrieved from: http: //www. thirteen.org/edonline/concept2class/ constructivism/index.html

- $\quad$ Tobias, (1993): Overcoming Math Anxiety. New York: w.w. Norton \& Company.

- $\quad$ Tobias, S. \& Weissbrod, C. (1980): Anxiety and Mathematics: an update, Harvard Educational review, 50(1), $63-70$

- $\quad$ Tobias, S. (1998). Anxiety and mathematics. Harvard Education Review. 50, 63-70.

- Tsui, J. M., \& Mazzocco, M. M. M. (2007). Effects of math anxiety and perfectionism on timed versus untimed math testing in mathematically gifted sixth graders. Roeper Review, 29(2), 132-139.

- $\quad$ Turner, J. C., Meyer, D. K., Anderman, E. M., Midgley, C., Gheen, M., Yongjin Kang, etal. (2002). The classroom environment and students' reports of avoidance strategies in mathematics: A multimethod study. Journal of Educational Psychology, 94(1), 88.

- $\quad$ Van, de, Walle, J. A., Folk, S., Karp, K. S., \& Bay-Williams, J. M. (2014 [2006]). Elementary and middle school mathematics: Teaching developmentally. Toronto: Pearson Canada Inc.

- Wigfield, A., \& Meece, J. L. (1988). Matha nxietyi n elementarya nd secondarys chool students. Journalof Educational Psychology, 80, 210-216.

- Woodard, T. (2004). The Effects of Math Anxiety on Post-Secondary Development Students as Related to Achievement, Gender, and Age. Inquiry, 9(1). ERIC Document Reproduction Service No. EJ876845.

- Zemelman, S., Daniels, H., \& Hyde, A. (1998). Best practice: New standards for teaching and learning in America's schools (2nd ed.). Portsmouth, NH: Heinemann. 